\title{
OS BENS DE INFORMAÇÃO E 0 PROBLEMA DA PRIMEIRA CÓPIA
}

\section{RESUMO}

O artigo apresenta um ensaio teórico de caráter exploratório dos bens de informação, categoria de produtos intensivos em informação, que uma vez digitalizados, podem ser dissociados das embalagens físicas nas quais são entregues, o que torna os custos marginais desprezíveis graças às mudanças na sua estrutura de custos de produção e distribuição eletrônica. A partir da compreensão das especificidades da estrutura de custos dos bens de informação, apresenta-se o chamado "problema da primeira cópia", que anuncia a existência de custos desprezíveis de produção de cópias adicionais uma vez que a cópia original tenha sido produzida. Finalmente, é colocada uma importante implicação para as firmas decorrente do problema da primeira cópia: a tradicional formação de preços com base em custos se torna inadequada, o que requer novas práticas organizacionais.

\section{Selma Carvalho CEPEAD/CAD/UFMG}

\footnotetext{
ABSTRACT The article presents a theoretical exploratory essay of information goods, which is the category of intensive information products wherein digitalized can be dissociated from the physical package in which they are delivered, a fact that diminishes marginal costs, thanks to the dramatic change in the electronic production and distribution cost structure. Considering the comprehension of the specificity of the information goods's cost structure, the so-called first-copy problem arises. This announces the existence of negligible marginal costs of production, once the original copy has already been produced. At last, the paper presents one important implication to the firms resulted from the first-copy problem: the traditional cost-based pricing inadequacy, which requires new organizational practices.
}

PALAVRAS-CHAVE Bens de informação, preço, custo, internet, comércio eletrônico. KEY WORDS Information goods, price, cost, internet, eletronic commerce. 


\section{O DESAFIO DE GERIR AS TROCAS IMATERIAIS NA ERA DO CONHECIMENTO}

Graças às recentes revoluções tecnológicas, a informação vem assumindo um papel cada vez mais importante na vida das pessoas ao redor do mundo. As novas tecnologias com base na microeletrônica entregaram à humanidade duas inovações que estão transformando a sociedade contemporânea: o processo de digitalização de dados e a Internet. Além de revolucionar o modo como produtos e serviços são comercializados, a combinação dessas duas tecnologias gerou pressões que ameaçam minar a estrutura de indústrias tradicionais de bens intensivos em informação, como por exemplo a indústria fonográfica. Além disso, o mercado eletrônico emergiu como o ambiente ideal para transacionar uma ampla gama de novos bens digitais.

$\mathrm{O}$ advento da Internet, ao mesmo tempo em que criou oportunidades para os empreendedores, lançoulhes desafios, especialmente no que se refere à gestão das trocas que envolvem os bens de informação no mercado virtual. Os sentimentos de decepção e frustração vividos desde a crise da Nasdaq transmitiram ao mundo a lição de que transformar o potencial de criação de novos produtos e serviços digitais com base na Internet em negócios lucrativos é uma tarefa árdua, que requer aprendizado e persistência. Nesse contexto, a academia deve assumir a função de construir teorias que entreguem à sociedade conhecimentos para auxiliar a compreensão da natureza das forças que atuam sobre os negócios de bens intangíveis de informação.

Estudos ligados aos bens de informação, incluindo temas relacionados a processos de negócios das empresas e a mercados digitais, pertencem a uma linha de pesquisa sobre comércio eletrônico que vem se desenvolvendo nos últimos anos e cuja perspectiva se baseia na análise econômica. Esse campo de pesquisa pode auxiliar a compreensão de fenômenos cuja interpretação com base em teorias convencionais é muitas vezes inadequada. O arcabouço teórico que vem ganhando corpo na atualidade pode ser utilizado por pesquisadores para avaliar diversas questões, como novos modelos de negócios digitais, mudanças nas fontes de rentabilidade das empresas e também propriedades dos bens de informação e dos mercados nos quais eles são transacionados (Kauffman e Walden, 2001). Além disso, segundo esses autores, a perspectiva econômica de análise do comércio eletrônico contribui para a pesquisa em diversos campos do conhecimento ligados à tecnologia da informação, tais como sistemas de informação, ciência da computação, economia, finanças, mercadologia, entre outros.

Com a intenção de contribuir para o entendimento dos fenômenos ligados às trocas imateriais de bens intensivos em informação realizadas em mercados eletrônicos e estimular reflexões e estudos acerca de problemas a eles relacionados, buscou-se neste ensaio conhecer, a partir de um estudo teórico de caráter exploratório, conceitos fundamentais que sustentam as teorias sobre os bens de informação.

Inicialmente, é feita uma revisão conceitual da expressão "bem de informação" procurando identificar suas principais características e articular definições dadas por diferentes autores. Num segundo momento, são apresentados fundamentos teóricos dessa categoria de bens intangíveis que explicam a existência de sua característica estrutural chamada de "o problema da primeira cópia", que é a possibilidade da firma de produzir e entregar bens de informação a custos unitários desprezíveis e praticamente constantes. Em seguida, procura-se mostrar porque o mercado eletrônico é um ambiente propício à guerra de preços entre organizações produtoras de bens de informação, o que tende a desencadear uma espiral decrescente de preços em direção a zero.

Uma vez conhecidos os contextos produtivo e mercadológico nos quais os bens de informação são transacionados, são apresentados recentes desenvolvimentos teóricos que buscam soluções para os desafios decorrentes do problema da primeira cópia lançados às organizações. Tais desafios suscitam novas práticas para estabelecer preços e desenvolver produtos na medida em que a formação de preços com base em custos se torna inadequada. Assim, com o objetivo de auferir receitas de vendas sustentáveis e garantir níveis satisfatórios de geração de valor econômico, bem como a sobrevivência no longo prazo, as empresas que atuam em mercados de bens de informação teoricamente dependem do desenvolvimento de competências inovadoras que permitam capturar uma fração suficiente do valor ofertado aos clientes substituindo a tradicional fórmula para formar preços que aplica um markup sobre os custos unitários.

\section{BEM DE INFORMAC̄̃O: CONCEITOS E CARACTERÍSTICAS}

Information good ou bem de informação é a expressão utilizada para se referir a produtos e serviços intensi- 
vos em informação, cujos custos marginais de produção são muito baixos ou próximos de zero (Bakos e Brynjolfsson, 2000; Kauffman e Walden, 2001) quando entregues via web (Gundepudi, Rudi e Seidmann, 2001) ou qualquer outra rede de telecomunicação, e que são comercializados como uma fonte primária de receita (Lopes e Galletta, 2002).

Bem de informação é qualquer coisa que puder ser digitalizada ou codificada como um fluxo de bits, e pela qual as pessoas estejam dispostas a pagar, independente da fonte particular de valor. Revistas, bancos de dados, filmes, músicas, softwares e páginas da web são considerados bens de informação (Shapiro e Varian, 1999).

Bem de informação é definido também como a categoria de produtos e serviços cuja fonte primária de valor para os consumidores consiste mais da porção digitalizável do que do meio pelo qual a informação se apresenta (Bhargava e Choudhary, 2001). Segundo os autores, o manuscrito da antiguidade descoberto recentemente, por exemplo, que é uma cópia grega original dos escritos de Arquimedes e cujo valor está no papel, não é um bem de informação.

Bem de informação é a categoria de produtos mais adequada à distribuição eletrônica, pois os mesmos podem ser integralmente digitalizados, descarregados da Internet pelos consumidores e enviados gratuitamente pelas redes de telecomunicação (Kauffman e Walden, 2001). As novas tecnologias possibilitaram dissociar o conteúdo dos bens de informação das suas usuais embalagens físicas, tais como livros e CDs (Shapiro e Varian, 1999). Assim, o conteúdo intangível digitalizado, que pode se constituir de dados, imagens, informações ou conhecimento, é passível de reprodução e disponibilizado ao usuário pela Internet.

Uma outra definição de bem de informação pode ser apresentada a partir da integração dos conceitos propostos pelos diversos autores: bem de informação é a categoria de produtos e serviços cuja fonte primária de valor e a disposição a pagar dos clientes residem nas informações ofertadas, que uma vez digitalizadas, podem ser dissociadas das embalagens físicas na qual são entregues, o que torna os custos marginais desprezíveis ou próximos de zero graças às mudanças na sua estrutura de custos de produção e distribuição eletrônica.

$\mathrm{Na}$ dimensão binária digital em que se encontram os bens de informação, revistas, filmes, músicas e jornais não têm significado, mas sim os números, palavras e imagens que são convertidos em bits ou seqüên- cias combinadas dos algarismos 1 e 0 (Negroponte, 2000). De acordo com o autor, deste ponto de vista, as pessoas são consumidoras de bits: a leitura de um livro consome cerca 3 milhões de bits por hora e ao se assistir televisão são consumidos os mesmos 3 milhões de bits, mas por segundo.

As características estruturais dos bens de informação mais relevantes para a compreensão da sua dinâmica competitiva são apresentadas por McGee e Bonnici (2002) e Shapiro e Varian (1999):

- Altos custos fixos de criação da primeira cópia ou da propriedade intelectual e custos marginais desprezíveis de reprodução e distribuição;

- Baixos custos para copiar a propriedade intelectual;

- A informação é um bem da experiência cada vez que é consumido. O conceito de bem da experiência se refere ao caso em que o julgamento de valor pelo consumidor depende da sua experimentação. Estratégias comerciais são implementadas para atender aos requisitos de experimentação de novos produtos, tais como amostras grátis e preços promocionais. Porém, a informação é considerada um bem da experiência toda vez que é consumida. Por exemplo, só depois da leitura de um jornal é que o leitor saberá se a edição vale o preço cobrado pelo mesmo. Nesse caso, a reputação associada à marca do produto é fundamental para reduzir a resistência dos consumidores à compra sem experimentação prévia;

- Com o fácil acesso à informação, que está disponível em excesso, o real valor adicionado pelo provedor para o usuário pode ser ampliado com a aplicação de tecnologias para facilitar a localização, filtragem e comunicação do que é útil a ele.

- São os vultosos investimentos em novas tecnologias e infra-estrutura, e não mudanças na natureza ou grandeza do estoque de informação existente, que possibilitam a ampliação do valor da informação na medida em que seu acesso se torna mais rápido e barato graças aos novos processos de produção e distribuição eletrônica.

- A precificação se dá preferencialmente em função do valor, em detrimento do tradicional procedimento com base em custos.

As características estruturais dos bens de informação resultam na ênfase no volume e na tendência de quedas sucessivas dos preços em direção a zero (McGee e Bonnici, 2002; Shapiro e Varian, 1999). De acordo com McGee e Bonnici (2002, p. 117): "Com base nestas características, tem havido uma mudança sistemá- 
tica e cada vez maior da tradicional economia industrial para uma economia com base em conhecimento ou economia da informação".

\section{O PROBLEMA DA PRIMEIRA CÓPIA}

\section{A incomum curva de custos dos bens de informação}

Um bem de informação possui sua curva de custos diferente da curva típica para os produtos convencionais (Turban et al., 2000). Segundo os autores, as curvas de custos da maioria dos serviços e produtos físicos têm formato de "U" (Figura 1.a). Inicialmente o custo médio decresce com o aumento da quantidade até atingir o ponto ótimo, no qual os mesmos são mínimos. A partir desse ponto, o custo médio assume valores crescentes devido ao aumento dos custos variáveis. De acordo com os mesmos autores, no caso dos bens de informação, a curva de custos médios se aproxima do formato de "C" porque os mesmos caem sucessivamente à medida que a quantidade aumenta (Figura 1.b).

A produção de um bem de informação envolve altos custos fixos de produção da primeira cópia e baixos custos variáveis e marginais de reprodução das cópias adicionais, que podem ser considerados desprezíveis ou negligenciáveis e também praticamente constantes independente da quantidade (Shapiro e Varian, 1999; Turban et al., 2000).

Assim, a queda contínua dos custos médios se dá em função da combinação entre a relativa constância dos baixos custos variáveis e o rateio dos altos custos fixos de produção da primeira cópia entre quantidades crescentes (Figura 2).

Esse fenômeno que acontece com os bens de informação digitais entregues pelas redes de telecomunicação é chamado de "o problema da primeira cópia": "uma vez que a primeira cópia da informação tenha sido produzida, cópias adicionais custam essencialmente nada" (Shapiro e Varian, 1999, p. 21).

As novas tecnologias provocaram um aumento substancial da participação dos custos fixos de produção da primeira cópia nos custos totais, pois bens de informação destituídos de forma física possuem custos desprezíveis de produção, empacotamento e entrega (Shapiro e Varian, 1998). Baye, Morgan e Scholten (2003) argumentam que em recente artigo escrito por eles em 2001 são apresentadas provas de que, mesmo em menor proporção, há custos fixos tipicamente requeridos para transmitir e adquirir informações na Internet, como por exemplo os custos mensais de manter servidores em funcionamento.

A estrutura incomum dos custos variáveis dos bens de informação decorre do fato de que se pode considerar que a capacidade de reprodução e entrega de cópias adicionais da informação original é praticamente ilimitada ou sem restrições consideráveis (Shapiro e Varian, 1999). A ausência de restrições de oferta faz com que as vendas dos bens de informação estejam limitadas apenas pela demanda (Gundepudi; Rudi e Seidmann, 2001). Por isso, para Shapiro e Varian

Figura 1 - Curvas de custos médios dos bens convencionais e dos bens de informação.

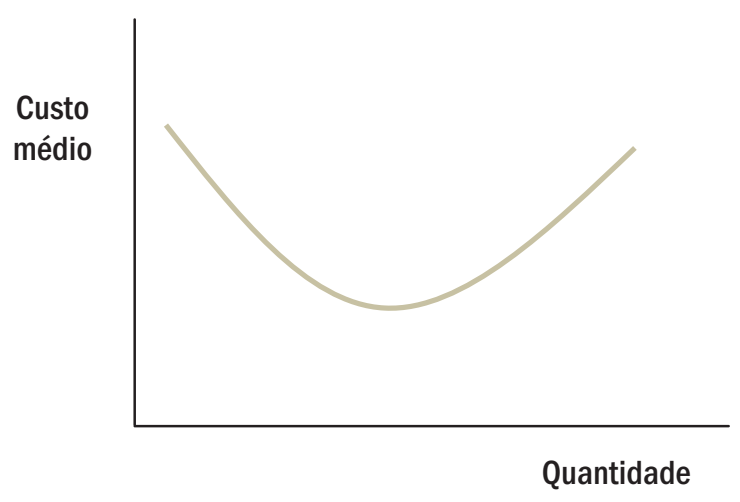

FIGURA 1.a - Produtos e serviços convencionais

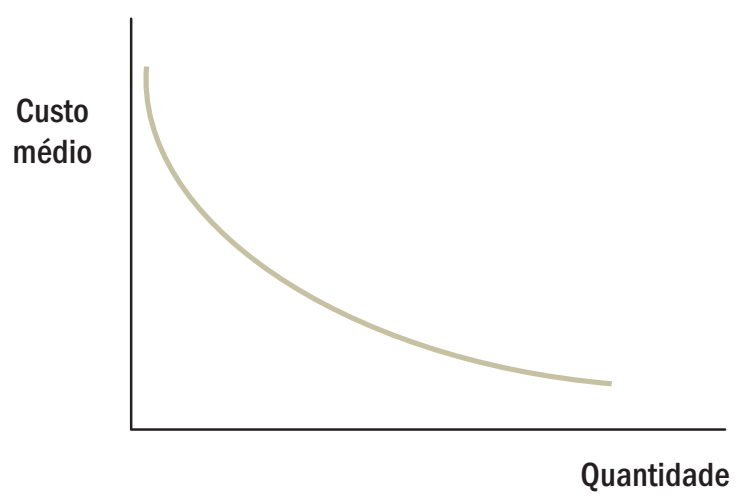

FIGURA 1.b - Bens de informação digitais 
(1999), o custo unitário de se reproduzir uma ou um milhão de cópias tem praticamente o mesmo valor.

Em função dos altos custos fixos de produção concentrados na primeira cópia e das economias de escala do lado da produção (Bakos e Brynjolfsson, 2000; Shapiro e Varian, 1999), a rentabilidade do negócio depende diretamente da existência de um número significativo de compradores (Turban et al., 2000). Economia de escala é a expressão que se aplica ao caso em que quanto maior a quantidade, menores os custos médios de produção. As vantagens de escala que se aplicam ao caso dos bens de informação podem ser consideradas um caso extremo do que se verifica em vários setores industriais tradicionais, desde companhias aéreas até serviços de telecomunicações (Shapiro e Varian, 1999).

No caso dos produtos convencionais, além das economias de escala, a redução de custos médios pode ser alcançada por meio da administração da cadeia de suprimentos e dos fluxos internos de trabalho. Mas no processo de produção de bens de informação, essas técnicas de gestão não contribuem significativamente para reduzir os custos da primeira cópia (Shapiro e Varian, 1999). Portanto, a alternativa-chave para reduzir custos é aumentar o volume de vendas (McGee e Bonnici, 2002; Shapiro e Varian, 1999).

Essas duas últimas proposições formuladas pelos autores citados acima podem ser questionadas se to- madas como regra geral. Ao introduzir a dimensão "tempo" no modelo conceitual que relaciona custos e quantidades produzidas de bens de informação, é possível identificar dois grupos distintos de firmas. O primeiro grupo se constitui de empresas que comercializam basicamente um mesmo bem de informação ao longo do tempo, tais como sites de pesquisa (Google e Yahoo!), provedores de acesso à Internet (Uol e Terra), enciclopédias virtuais e guias de ruas, mapas e endereços (Apontador). Após a produção da cópia original, elas precisam arcar com custos significativamente mais baixos de armazenamento e atualização do conteúdo. Tais organizações podem ser consideradas casos típicos do modelo proposto para a firma que está sujeita ao problema da primeira cópia, pois os altos custos fixos de produção são empreendidos em um ponto no tempo.

Mas uma empresa que atua no mercado cinematográfico, ou até mesmo uma emissora de TV como a Rede Globo, por exemplo, cuja produção de novas cópias originais é contínua devido à grande demanda por novos lançamentos a cada temporada, está sempre sujeita a altos custos fixos da primeira cópia. Ou seja, há uma produção em série de primeiras cópias. Este é o segundo grupo, cujos ciclos produtivos de diferentes bens de informação parecem ser interdependentes, pois as receitas de vendas de versões acabadas em determinado período, mesmo depois de amortiza-

Figura 2 - Composição dos custos dos bens de informação digitais.

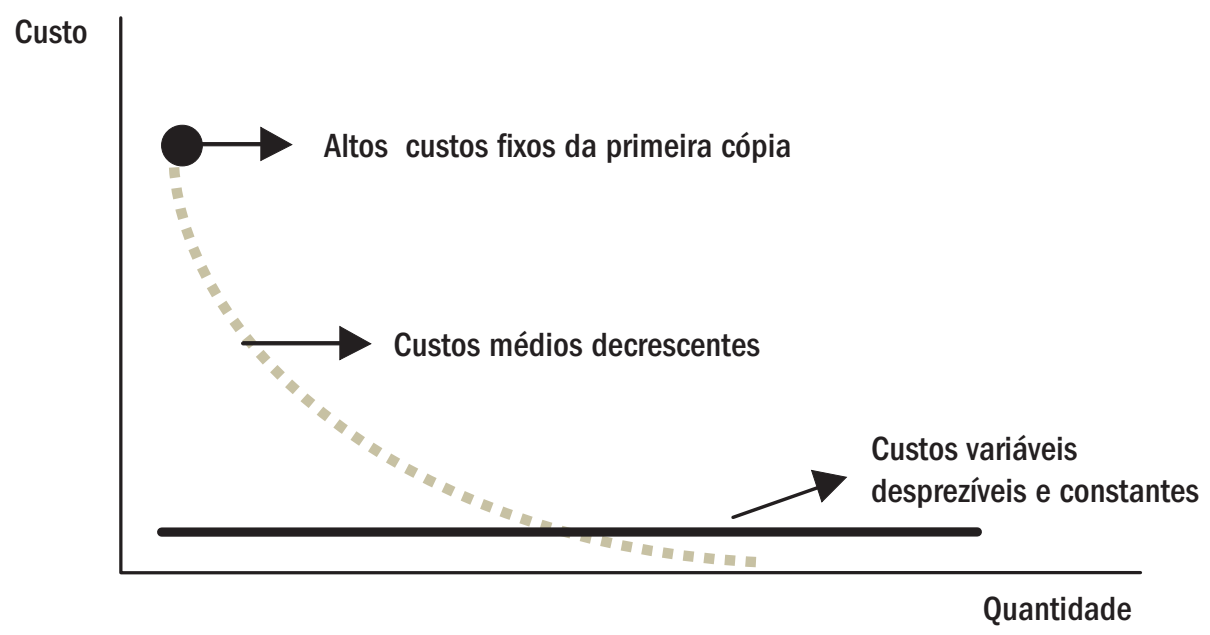

$2004 \cdot$ ORAE $\cdot 101$ 
dos os custos de produção de sua própria cópia original, possivelmente financiam os custos fixos da primeira cópia de outras versões em fase de construção.

Neste caso, ao contrário do que propõem Shapiro e Varian (1999), a gestão da cadeia de suprimentos e dos processos internos de trabalho é importante para reduzir os custos médios, não de reprodução e entrega eletrônica de cópias disponíveis no mercado virtual, mas de produção contínua de cópias originais. Portanto, apesar de atuar em mercados de bens de informação e estar sujeito ao problema da primeira cópia, o segundo grupo de empresas, em função da necessidade permanente de financiamento da produção de versões originais, não deve apresentar uma estrutura de custos médios totais - referente a todo o conjunto de bens de informação que elas produzem e comercializam - que possa ser considerada continuamente decrescente em direção a valores desprezíveis à medida que a quantidade vendida de cópias originais reproduzidas aumenta. Assim, nesse caso, a gestão interna dos processos internos de trabalho e da cadeia de suprimentos é tão importante quanto a ênfase na quantidade para reduzir custos.

Uma outra análise relativa à estrutura conceitual de custos de uma empresa produtora de bens de informação pode ser feita a partir da substituição da variável "quantidade" por "qualidade". Para Bhargava e Choudhary (2001), aos moldes da Figura 1.b, a curva de custos marginais para um bem de informação será provavelmente uma função côncava da qualidade, já que os custos de reproduzir um bem de alta qualidade e outro de qualidade inferior são praticamente os mesmos. Assim, a taxa custo/qualidade irá provavelmente declinar com o aumento da qualidade.

\section{Competição por preços em mercados eletrônicos}

O mercado digital na Internet é formado por sistemas de informação que cruzam as fronteiras organizacionais interligando organizações, clientes e fornecedores. É também conhecido como IIS - Interorganization Information Systems (Bakos, 1991).

Os mercados eletrônicos são particularmente adequados para a comercialização dos bens de informação porque os mesmos se beneficiam da digitalização do mecanismo de mercado e também do mecanismo de distribuição, o que garante custos de transação extremamente baixos (Turban et al., 2000). Segundo os autores, além de provocar mudanças em muitos processos mercadológicos, a emergência do mercado eletrônico na Internet resultou em grandes eficiências econômicas em virtude da redução dos custos de vários processos que suportam as trocas.

Porém, um ponto crítico que deve ser observado com atenção a fim de garantir a funcionalidade e o crescimento das transações no mercado eletrônico se refere aos aspectos de segurança e privacidade das informações que trafegam pelas redes de comunicação, o que inclui problemas relacionados às questões legais de propriedade intelectual (Albertin e Moura, 1998). De acordo com os autores, iniciativas públicas e privadas nesse sentido são importantes para garantir condições favoráveis à utilização do comércio eletrônico pelas empresas como uma forma de alcançar vantagens competitivas.

O maior impacto do mercado virtual é a redução dos custos de pesquisa por informações sobre preços, produtos e vendedores: "esta redução nos custos de busca tem um papel importante na determinação das implicações desses sistemas para a eficiência do mercado e para o comportamento competitivo" (Bakos, 1991, p. 295). De acordo com o mesmo autor, em mercados cuja competição baseia-se essencialmente em preços, a introdução de um sistema que disponibiliza gratuitamente informações em tempo real para compradores pode levar à redução dos preços dos bens e dos lucros dos vendedores, além de ampliar o bemestar dos compradores.

Ao mesmo tempo em que reduz drasticamente os custos de distribuição dos bens de informação, a Internet se constitui em um mercado propício à guerra de preços entre empresas que lutam para aumentar o volume de transações procurando diluir os altos custos fixos (Porter, 2001, p. 66):

as tecnologias da Internet tendem a reduzir custos variáveis e alterar as estruturas de custos, criando significativas pressões para as companhias se lançarem em uma competição via preços destrutiva [...] O grande paradoxo da Internet é que seus maiores benefícios - tornar a informação amplamente disponível; reduzir a dificuldade de comprar, comercializar e distribuir, permitindo que compradores e vendedores se encontrem e efetuem transações uns com os outros de forma mais fácil - também dificulta a captura pelas empresas desses benefícios na forma de lucros.

Uma vez que as empresas tenham recuperado os investimentos necessários para produzir a primeira có- 
pia do bem de informação, as forças competitivas tendem a colocar o preço em uma espiral descendente em direção ao valor do custo marginal, que é próximo de zero no caso dos bens entregues pelas redes de telecomunicação, o que explicaria a grande oferta de informações gratuitas na Internet (Shapiro e Varian, 1999).

Um exemplo dado pelos mesmos autores é a queda vertiginosa dos preços da enciclopédia Britânica após o lançamento no mercado pela Microsoft em 1992 da enciclopédia digital Encarta, que passou a ser vendida a U\$ 45 em CD-ROM aos usuários finais e também foi oferecida como brinde por alguns fabricantes de computador. A enciclopédia Britânica, que antes era vendida por U\$ 1.600 em 32 volumes impressos, perdeu cerca da metade das receitas de vendas para a versão digitalizada do concorrente. Depois de vendida, a nova empresa proprietária da Britânica lançou entre 1995 e 1996 versões digitais do produto, tanto em CD-ROM quanto online e seu preço chegou a U\$ 89,99.

O preço da versão online da Britânica pode cair ainda mais se a disposição a pagar dos consumidores diminuir em função do acesso gratuito a serviços de pesquisa em sites da Internet. Mas, conforme argumentam McGee e Bonicci (2002), a queda dos preços em direção ao custo marginal de reprodução da versão digital dessa enciclopédia pode ser evitada pelos sinais de qualidade e reputação emitidos pelo nome Britânica ao mercado.

Um estudo feito por Baye, Morgan e Scholten (2003) a partir da manipulação de dados referentes às informações de uma empresa norte-americana fornecedora de comparações de preços online mostrou que os consumidores podem economizar aproximadamente 16\% na compra de produtos eletrônicos se utilizarem esse serviço. Os autores apontam para a questão dos custos sociais da exclusão digital, que não dá acesso a este tipo de benefício às pessoas que não participam do mercado eletrônico. No caso do Brasil, este problema é ainda mais preocupante, pois pesquisas indicam que apenas cerca de $7 \%$ da população brasileira utiliza a Internet (Ramos e Costa, 2000).

\section{A formação de preços para os bens de informação}

Em decorrência do problema da primeira cópia, uma empresa que atua em mercados competitivos de bens de informação digitais teoricamente está sujeita a um outro problema: a tradicional formação de preços com base em custos se torna inviável na medida em que os custos marginais de produção de uma cópia adicional assumem valores desprezíveis ou próximos de zero (Kauffman e Walden, 2001; Shapiro e Varian, 1999). "A precificação baseada em custos não funciona: uma margem de lucro de $10 \%$ ou $20 \%$ sobre os custos unitários não faz sentido quando estes são nulos" (Shapiro e Varian, 1999, p. 3). Além disso, precificar os bens de informação tomando como base os concorrentes significa inflamar a competição e tomar o caminho em direção à ruína (Shapiro e Varian, 1998).

Se a lógica da formação de preços com base em custos tomando como referência os valores praticados pelos concorrentes não é adequada para os bens de informação, uma alternativa teórica proposta é estabelecer preços baseando-se no valor atribuído pelos clientes aos artigos digitais, uma vez que:

O preço não será igual a zero a menos que o produto realmente não tenha valor [...] A formação de preços depende de quão valioso um produto é para o seu comprador, a despeito do seu custo de produção (Turban et al., 2000, p. 435). Deve-se estabelecer o preço dos bens de informação de acordo com o valor que os consumidores dão a eles, e não com base nos custos de produção (Shapiro e Varian, 1999, p. 3).

De acordo com os últimos autores citados acima, a precificação com base no valor conduz naturalmente às práticas organizacionais de discriminação de preços, que é cobrar diferentes preços de compradores cujo julgamento de valor é diferenciado (Turban et al., 2000).

Tentando superar o problema da primeira cópia, muitas empresas "ponto-com" adotaram uma estratégia com foco na venda de espaço publicitário como fonte principal de receitas. Porém, segundo Porter (2001), os anunciantes estão se tornando mais seletivos, o que está fazendo a taxa de crescimento dos anúncios na Internet cair, prejudicando a capacidade de geração de receitas sustentáveis pelas empresas fornecedoras de bens de informação. Assim, uma alternativa mais promissora é desenvolver a capacidade organizacional de personalizar produtos e serviços, compondo linhas de bens de informação com diferentes versões - inclusive online e off-line - e combiná-la à habilidade de acessar e modelar informações substanciais sobre compradores atuais e potenciais (Turban et al., 2000). De acordo com os autores, isto é a base para se desenvolver a competência em discriminar preços.

Além de buscarem se beneficiar das vantagens das 
economias de escala por meio da ênfase no volume em virtude da necessidade de diluir os custos da primeira cópia, as organizações provedoras de bens de informação podem se aproveitar também de economias de escala do lado da demanda para capturar uma fração maior dos diferentes valores atribuídos a eles pelos clientes adotando estratégias ligadas ao desenvolvimento de produtos.

Um tipo de economia de escala do lado da demanda conhecida como economy of aggregation, pode ser criada pelas empresas se os bens de informação forem comercializados em pacotes (Bakos e Brynjolfsson, 2000, p. 63):

para a maior parte dos bens tangíveis, cujos custos marginais são significativos, o impacto potencial da agregação em larga escala é limitado. No entanto, nós identificamos que esses efeitos podem ser decisivos para o sucesso ou o fracasso dos bens de informação.

Os autores argumentam que no caso de produtos cujos custos marginais são muito baixos ou próximos de zero, como é o caso dos bens de informação digitais, é mais fácil para os vendedores preverem como os compradores avaliarão uma coleção de bens do que fazerem a mesma previsão para um artigo individualmente. Assim, é possível reduzir a incerteza sobre os diferentes julgamentos de valor e melhorar a eficácia da precificação (Myerson, 1983 apud Bakos e Brynjolfsson, 1999).

Comercializar bens de informação em pacotes promete trazer outros benefícios às empresas, como economias de custo de transação, complementaridade entre os produtos componentes e também a classificação de consumidores segundo suas atribuições de valor (Hanson, 1990 apud Bakos e Brynjolfsson, 1999).

Os resultados do modelo proposto por Bakos e Brynjolfsson (1999) mostram que um vendedor de informação pode extrair dos compradores mais valor de cada artigo quando ele é parte de um pacote de bens não-correlacionados, composto por um significativo número de bens de informação, do que no caso em que eles são vendidos separadamente. Assim, as empresas que adotarem a estratégia chamada bundling, que é precificar e comercializar dois ou mais produtos e serviços agrupados em um pacote (Stremersch e Tellis, 2002), terão melhores condições de alcançar níveis mais altos de rentabilidade:
Nós analisamos as estratégias ótimas de formação de pacotes [...] e chegamos à conclusão que um pacote com um grande número de bens de informação não-relacionados pode ser bastante lucrativo [...] Como resultado disso, o valor projetado dos pacotes torna possível alcançar maiores vendas, maior eficiência econômica [...] Nossos principais resultados não podem ser aplicados à maior parte dos bens tangíveis [...] Oferecendo opções de diferentes pacotes direcionados a cada segmento do mercado, o empacotamento torna a estratégia tradicional de discriminação de preços mais eficaz (Bakos e Brynjolfsson, 1999, p. 1613).

De acordo com os mesmos autores, a Internet torna viável economicamente a formação de pacotes de diferentes tipos de informação. Além disso, provedores de informação podem adotar diferentes estratégias de preços e pacotes em diferentes mídias eletrônicas usadas para entregar o conteúdo. A demonstração teórica dada pelos autores para a força da formação de pacotes de bens de informação se pauta na lógica de que o julgamento de valor dos consumidores atribuído a uma coleção de bens tem uma distribuição de probabilidade com uma menor variância se comparada às avaliações por produto ou serviço.

Criar diferentes versões da mesma informação preservando o seu conteúdo central e adaptando-as às necessidades de diferentes consumidores é um procedimento que permite diferenciar produtos e serviços protegendo as empresas contra a competição que leva ao colapso de preços (Shapiro e Varian, 1998). E além do tradicional critério de criação de versões de diferentes preços para os bens de informação segundo julgamentos de valor dos benefícios relacionados à antecedência de compra ou recebimento - delay -, os autores apresentam outros critérios que podem ser combinados: conveniência, nível de profundidade e detalhamento das informações fornecidas, facilidade de manipulação das informações, oportunidade de compartilhar e discutir as informações com outras pessoas que têm os mesmos interesses, possibilidade de evitar o recebimento de anúncios indesejados e irritantes, velocidade de funcionamento de programas, capacidade de processamento de dados, forma de acesso às informações desejadas - interface - resolução de imagens e suporte técnico.

Os mesmos autores citados acima fazem referência à oportunidade proporcionada às organizações pelos 
custos extremamente baixos de criação e distribuição em larga escala de versões incompletas e gratuitas dos bens de informação com o objetivo de atender às necessidades de teste e experimentação prévios dos compradores. Essa atividade pode neutralizar os efeitos negativos da característica da informação de ser um "bem da experiência" toda vez que é consumido.

Se adotar políticas de discriminação de preços e comercialização de diferentes versões ou pacotes é uma alternativa às empresas convencionais para aumentar a rentabilidade do negócio através da segmentação de mercado, no caso das empresas provedoras de bens de informação, as mesmas são essenciais para fugir da concorrência que tende a levar os preços para zero. De acordo com Baye, Morgan e Scholten (2003, p. 18):

muitos artigos recentes sugerem que as firmas deveriam evitar esse resultado através da discriminação de preços para tirar proveito da heterogeneidade dos clientes (Baylis and Perloff, 2002) ou ofuscar a informação quanto aos preços (Ellison e Ellison, 2001).

De acordo com Bhargava e Choudhary (2001), existem três níveis de discriminação de preços. No primeiro, a organização conhece a atribuição de valor de cada consumidor dada ao produto ou serviço e cobra um preço personalizado pelo mesmo artigo, que é igual a cada valor atribuído individualmente. No segundo, o processo de discriminação de preços, que é a prática mais comum inclusive para bens convencionais, e também conhecido como diferenciação vertical, se dá no caso em que a firma conhece apenas a distribuição agregada dos julgamentos de valor dos consumidores e não os julgamentos individuais ou por segmento de clientes. No terceiro nível, a discriminação ocorre quando a empresa pode observar os sinais da demanda agregada de certos segmentos de consumidores e se torna hábil para cobrar diferentes preços de cada segmento.

De acordo com os mesmos autores, a discriminação de preços de segundo nível para bens de informação pode seguir critérios de qualidade. Nesse caso, os consumidores aceitam a ordem da combinação preço/qualidade das versões ofertadas e escolhem a composição que lhes é mais adequada. Cobrar diferentes preços segundo o prazo de antecipação da compra (forward e spot buying) também é um critério de discriminação de segundo nível que pode ser adequado aos bens de informação, como por exemplo, os programas de TV a cabo, que incluem assinaturas mensais e pay-per-view (Gundepudi, Rudi e Seidmann, 2001).

O estudo de Bhargava e Choudhary (2001) mostrou que, sob determinadas circunstâncias, a linha ótima de bens depende da taxa custo/benefício das qualidades. Além disso, os autores concluíram que a discriminação de preços de segundo nível não é ótima quando o produto de maior qualidade possui a melhor taxa custo/benefício, caso em que se encontram muitos bens de informação. Os resultados apresentados pelos autores, conforme citação dos mesmos, contrariam demonstrações feitas por diversos pesquisadores de que a diferenciação vertical pode não ser a solução ótima de precificação para os bens de informação.

Um outro meio de discriminar preços de forma lucrativa é explorar a facilidade com que os bens de informação podem ser alugados ou compartilhados entre indivíduos utilizando as vantagens oferecidas por diversos tipos de instituições sociais, como bibliotecas e universidades. Para Varian (2000), a existência de tais instituições pode ser benéfica aos produtores de bens de informação, pois uma redução na demanda dos indivíduos pode, em determinadas condições, ser mais que compensada pelo incremento no preço que elas se dispõem a pagar. Segundo o autor, modelos de cálculo do preço socialmente ótimo para bens de informação compartilhados são adequados para estabelecer preços de jornais e bases de dados acadêmicos.

\section{CONSIDERAÇÕES FINAIS}

Ao olhar para o futuro, as empresas brasileiras que atuam ou eventualmente atuarão em mercados eletrônicos de bens de informação com base na Internet precisam estar preparadas para competir em um contexto produtivo diferenciado, cuja estrutura de custos pode apresentar uma especial configuração em decorrência da digitalização dos processos de produção, venda e distribuição eletrônica dos mesmos. Com efeito, torna-se importante utilizar conhecimentos que permitam avaliar os impactos do comércio eletrônico de produtos e serviços intensivos em informação sobre a estrutura da indústria, da dinâmica competitiva e da própria organização.

Ao mesmo tempo em que apontam para uma estrutura operacional mais enxuta em algumas empresas que atuam em mercados de bens de informação em decorrência dos impactos sobre processos internos li- 
gados à reprodução, comercialização e entrega, a introdução de tecnologias de informação com base na microeletrônica para transacionar informações indica a necessidade de desenvolvimento de outros processos organizacionais, que requerem pessoal cada vez mais qualificado. Como exemplos podem-se citar as atividades de extração e manipulação de dados para suportar decisões ligadas à discriminação de preços, que por sua vez está pautada na habilidade de segmentar o mercado e construir versões segundo os diferentes julgamentos de valor dos compradores.

Além disso, se no caso de mercadorias convencionais o cliente tem a opção de escolher pagar por um artigo dentre substitutos de preços diferenciados, no caso dos bens de informação ele pode, em muitas situações, escolher entre pagar ou adquirir gratuitamente o bem desejado. Assim, mesmo que a maior fração do valor resida no conteúdo da informação, que pode ser obtida pelo usuário sem necessidade de sua contrapartida monetária, é importante agregar-lhe serviços complementares para incentivá-lo a pagar pela informação.

É importante salientar que muitos produtos e serviços continuam surgindo ou se transformando em bens de informação digitais, como, por exemplo, cursos a distância e sequêencias genéticas. Nesse contexto, os impactos das novas tecnologias sobre os mercados de informação são exercidos em duas frentes: por um lado oferecem às empresas a possibilidade de reproduzir e distribuir bens de informação a custos próximos de zero e de obter lucros extraordinários na medida em que consigam solucionar problemas de formação de preços e de geração de receitas sustentáveis; mas sua outra face é a ampliação da possibilidade de usufruto social dos custos desprezíveis de reprodução da primeira cópia.

Assim, outro desafio colocado às empresas produtoras de bens de informação em virtude da digitalização e da existência da Internet é o fato de que tanto reproduzir quanto copiar são processos que geram versões perfeitas da cópia original (Shapiro e Varian, 1999). A diferença é que a reprodução é uma ação legal, e a cópia, não. A capacidade de controle e exploração comercial dos bens de informação, garantida às organizações pelos direitos legais de propriedade intelectual por meio da concessão de patentes e direitos autorais, se enfraqueceu diante do potencial da Internet de gerar cópias ao redor do mundo. Segundo Deccax, Fontes e Nogueira (2003), a pirataria digital por meio de novos programas de tecnologia ponto-a-ponto agravou ainda mais o problema.

$\mathrm{Na}$ verdade, os limites impostos à gestão da propriedade intelectual pelas empresas se relacionam diretamente a uma questão mais ampla colocada à sociedade: a informação pode ser um bem público, que não requer exclusividade no uso - o compartilhamento da informação por uma pessoa não reduz sua própria quantidade de informação (Allen, 1990). Assim, mesmo que o aparato jurídico-institucional se torne mais sofisticado e eficaz no controle da disseminação das cópias ilegais, as empresas precisam, da mesma forma que a precificação, desenvolver novas práticas para conviver com os "piratas digitais", que na maioria das vezes são os seus próprios clientes e consumidores. Nesse contexto, o crescimento da riqueza para a firma pautado na produção e comercialização de bens de informação depende da solução de um impasse: os altos custos da primeira cópia são privados e o usufruto dos benefícios advindos da utilização da informação tende a se tornar imediatamente público e gratuito.

Contudo, mesmo diante de fracassos e decepções experimentados pelos pioneiros que se lançaram no mercado virtual baseado na Internet, os estudos acadêmicos relativos às transações de bens intangíveis intensivos em informação têm continuado com vigor nos países industrializados, como pode ser comprovado pela recente literatura referenciada neste trabalho. Percebe-se que o passado recente deixou experiências e lições importantes, e é essencial aprendêlas rapidamente para prosseguir com firmeza em direção ao sucesso no futuro. Nesse contexto, tornase importante incentivar pesquisas no campo da Administração sobre temas ligados aos bens de informação de modo a promover a geração de conhecimentos que atendam às necessidades de reformulação organizacional e desenvolvimento de novas habilidades e competências pelas empresas brasileiras do ramo.

Artigo recebido em 26.09.2003. Aprovado em 09.01.2004.

\section{Referências bibliográficas}

ALBERTIN, A. L.; MOURA, R. M. Comércio eletrônico: seus aspectos de segurança e privacidade. Revista de Administração de Empresas, v. 38, n. 2, p. 49-61, 1998.

ALLEN, B. Information as an economic commodity. American Economic Review, v. 80, n. 2, p. 268-274, 1990. 
BAKOS, Y. A strategic analysis of eletronic marketplaces. MIS Quartely, v. 15, n. 3, p. 295-311, 1991.

BAKOS, Y.; BRYNJOLFSSON, E. Bundling information goods: pricing, profits, and efficiency. Management Science, v. 45, n. 12, p. 1613-1631, 1999.

BAKOS, Y.; BRYNJOLFSSON, E. Bundling and competition on the internet. Marketing Science, v. 19, n. 1, p. 63-82, 2000.

BHARGAVA, H., CHOUDHARY, V. Information goods and vertical differentiation. Journal of Management Information System, v. 18, n. 2, p. 89-106, 2001.

BAYE, M. R.; MORGAN, J.; SCHOLTEN, P. The value of information in an online consumer eletronics market. Journal of Public Policy \& Marketing, v. 22, n. 1, p. 17-25, 2003.

BAYLIS, K.; PERLOFF, J. M. Price dispertion on the Internet: good firms and bad firms. Review of Industrial Organization, v. 21, n. 3, p. 305-324, 2002. In: BAYE, M.R., MORGAN, J., SCHOLTEN, P. The value of information in an online consumer eletronics market. Journal of Public Policy \& Marketing, v. 22, n. 1, p. 17-25, 2003.

DECCAX, R. A.; FONTES, E. A. N.; NOGUEIRA, A. R. R. A reconfiguração da indústria de entretenimento eletrônico doméstico. In: ENCONTRO NACIONAL DE PROGRAMAS DE PÓS-GRADUAÇÃO EM ADMINISTRAÇÃO, 27, 2003, Atibaia. Anais eletrônicos...Rio de Janeiro: ANPAD, 2003. CD-ROM.

ELLISON, G.; ELLISON, S. F. Search, obfuscation and price elasticities on the Internet. Working paper, Massachussets Institute of Technology, 2001. In: BAYE, M. R.; MORGAN, J.; SCHOLTEN, P. The value of information in an online consumer eletronics market. Journal of Public Policy \& Marketing, v. 22, n. 1, p. 17-25, 2003.

GUNDEPUDI, P.; RUDI, N.; SEIDMANN, A. Forward versus spot buying of information goods. Journal of Management Information Systems, v. 18, n. 2, p. 107-131, 2001.

HANSON, W. K. M. Optimal bundle pricing. Management Science, v. 36, n. 2, p. 155-174, 1990. In: BAKOS, Y., BRYNJOLFSSON, E. Bundling information goods: pricing, profits, and efficiency. Management Science, v. 45, n. 12, p. 1613-1631, 1999.
KAUFFMAN, R. J.; WALDEN, E. A. Economics and eletronic commerce: survey and directions for research. International Journal of Eletronic Commerce, v. 5, n. 4, p. 5-116, 2001.

LOPES, A. B.; GALLETA, D. Information value in eletronic networks: the case of subscription-based online information goods. Academy of management proceedings, p. D1, 2002.

McGEE, J.; BONNICI, T. A. Network industries in the new economy. European Business Journal, v. 14, n. 13, p. 116-133, 2002.

MYERSON, R. B. S. Efficient mechanisms for bilateral trading. Journal of Economic Theory, v. 28, n. 1, p. 265-281, 1983. In: BAKOS, Y.; BRYNJOLFSSON, E. Bundling information goods: pricing, profits, and efficiency. Management Science, v. 45, n. 12, p. 1613-1631, 1999.

NEGROPONTE, N. Will everything be digital? Time, v. 155, n. 25, 2000.

PORTER, M. Strategy and the Internet. Harvard Business Review, v. 79, n. 3, p. $62-78,2001$.

RAMOS, A. S. M.; COSTA, F., H., A. Serviços bancários pela Internet: um estudo de caso integrando a visão de competidores e clientes. Revista de Administração Contemporânea, v. 4, n. 3, p. 133-154, 2000.

SHAPIRO, C.; VARIAN, H. Versioning: the smart way to sell information. Harvard Business Review, v. 76, n. 6, p. 107-129, 1998.

SHAPIRO, C.; VARIAN, H. Information Rules: a strategic guide to the network economy. Boston: Harvard Business School Review Press, 1999.

STREMERSCH, S.; TELLIS, G. J. Strategic bundling of products and prices: a new synthesis for marketing. Journal of Marketing, v. 66, n. 1, p. 55-72, 2002

TURBAN, E. et al.. Eletronic commerce: a managerial perspective. Upper Saddle River, New Jersey: Prentice Hall, 2000.

VARIAN, H. R. Buying, sharing and renting information goods. Journal of Industrial Economics, v. 48, n. 4, p. 473-489, 2000.

\section{Selma Carvalho}

Mestranda em Administração pelo CEPEAD/CAD/UFMG e pesquisadora do Núcleo interdisciplinar sobre gestão em organizações não-empresariais (Nig.one) da UFMG. Interesses de pesquisa em mercados e organizações produtoras de bens de informação, ensino a distância e a perspectiva teórica da visão com base em recursos.

E-mail: sc@cepead.face.ufmg.br

Endereço: Rua Curitiba, 832, 11ํandar - Centro Belo Horizonte, MG, 30170-120. 